\title{
Kendali Motor DC Brushless Modifikasi Mengunakan IC Ne555 Dan CD4017
}

\author{
Wiwin A. Oktaviani ${ }^{1}$, Sukri Basri ${ }^{2}$ \\ ${ }^{1,2}$ Prodi Teknik Elektro, Fakultas Teknik Universitas Muhammadiyah Palembang \\ Jl. Jend A. Yani 13 UIU Palembang \\ ${ }^{1}$ wiwin_oktaviani@um-palembang.ac.id \\ 2ibnusukri33@gmail. com
}

\begin{abstract}
Intisari - Pada umumnya pengontrol kecepatan motor Brushless DC menggunakan mikrokontroler ATMEGA 16 dan MOSFET yang sering kali meningkatkan temperatur MOSFET, terutama saat motor dibebani. Artikel ini membahas tentang penggunaan IC NE555 dan CD4017 sebagai pengatur frekuensi ke gerbang MOSFET dengan cara menyalakan tegangan maju secara berkala dari perubahan nilai potensiometer. Pengujian dilakukan dalam keadaan bongkar muat dengan variasi tegangan 2.5 Vac, 7.5 Vac, 12.5 Vac, dan 19.5 Vac. Hasil pengujian menunjukkan respon pahat sangat baik dimana semakin tinggi nilai frekuensinya maka kecepatan motor akan meningkat. Kecepatan maksimum saat dibongkar mencapai rpm pada frekuensi 574,6. Sedangkan pada pengujian beban kecepatan penuh mencapai $2.0987 \mathrm{rpm}$ pada frekuensi 524.675 Hz. Selama pengujian, tidak ada kenaikan suhu di MOSFET
\end{abstract}

Kata Kunci - IC NE555, CD4017 dan Motor DC Brushless

Abstract - In general, the Brushless DC motor speed controller uses an ATMEGA 16 microcontroller and a MOSFET, which often increases the MOSFET's temperature, especially when the motor is loaded. This article discusses the use of the IC NE555 and CD4017 as a frequency regulator to the MOSFET gate by periodically igniting the forward voltage from the change in the potentiometer value. We carried out the test in an unloaded and unloaded state with voltage variations of $2.5 \mathrm{Vac}, 7.5 \mathrm{Vac}, 12.5 \mathrm{Vac}$, and $19.5 \mathrm{Vac}$. The test results show an excellent tool response where the higher the frequency value, the motor speed will increase. The maximum speed when unloaded reaches rpm at a frequency of 574.6. Whereas in the load test, the full speed reaches $20987 \mathrm{rpm}$ at a frequency of $524.675 \mathrm{~Hz}$. During the test, there was no temperature increase in the MOSFET.

Keywords - IC NE555, CD4017 dan Motor DC Brushless

\section{PENDAHULUAN}

Penggunaan motor direct current (DC) brushless memiliki banyak keunggulan dibandingkan motor DC konvensional. Efisiensi yang tinggi dan rugi-rugi mekanik yang rendah membuat motor ini banyak digunakan dalam berbagai keperluan seperti dalam otomotif, aerospace, kesehatan, industri dan instrumentasi. Sesuai namanya motor BLDC tidak memiliki sikat pada komutatornya. Sebagai gantinya digunakan komutator elektrik. Kelemahan penggunaan motor DC konvensional membutuhkan penggantian sikat secara periodik untuk menjaga kinerja motor DC dan menghindari terjadinya busur api.
Motor BLDC memiliki beberapa keuntungan jika dibandingkan dengan motor DC konvensional yaitu karakteristik kecepatan dan torsi yang lebih baik, respon dinamik yang tinggi, efisiensi tinggi, umur pakai yang panjang, rendahnya tingkat noise dan jangka kecepatan yang lebar.

Penggunaan motor DC Brushless bukan tanpa masalah. Rangkaian penyearah pada motor DC jenis ini sering menyebabkan buruknya nilai faktor daya dan menimbulkan masalah-masalah harmonic. Penggunaan konverter seperti SEPIC [1] dan pemasangan DC-DC konverter antara rectifier dan inverter [2] mampu memperbaiki nilai Total Harmonic Distorsion (THD).

Pengendali motor DC yang banyak dipakai adalah pengendali berbasis Pulse Wave 
Modulation $(P W M)$. Prinsip kerjanya adalah mengatur kecepatan motor DC dengan mengatur duty cycle, yang berpengaruh terhadap tegangan motor DC. Perubahan tegangan diikuti perubahan arus yang pada akhirnya akan mempengaruhi besaran torsi motor[3]. Untuk meningkatkan kinerja, PWM umumnya dikombinasikan dengan Arduino Uno [4][5][6].

Pengaturan besaran fluks yang dihasilkan kumparan motor DC menggunakan juga dapat digunakan untuk mengatur kecepatan motor DC brushless ini. Pengaturan fluks dilakukan oleh kontrol PI guna mendapatkan besaran fluks yang sama dengan nilai set pointnya [7].

Selain pemilihan komponen elektronika yang tepat, perancangan algoritma yang baik akan meningkatkan efektifitas pengendalian pergerakan motor DC [8]

Umumnya kendali kecepatan putar Motor Brushless DC mengunakan microcontroller ATMEGA 16 dan MOSFET [9]. Permasalahan yang sering timbul adalah daya yang menimbulkan disipasi panas pada MOSFET yang dapat mengurangi kinerja alat. Penyebab panas lainnya adalah pergantian kondisi on - off atau sebaliknya. Kondisi ini menyebabkan mosfet berada pada kondisi $1 / 2$ on dan $1 / 2$ off [10].

Pada penelitian ini kecepatan motor DC Brushless diatur dengan pengontrol IC NE555 dan CD4017 sebagai pengatur frekuensi masuk gate MOSFET (Metal Oxide Semiconductor Field-Effect Transistor).

\section{METODE PENELITIAN}

Motor DC yang digunakan pada penelitian ini adalah Motor DC Brushless hasil modifikasi, dengan cara mengubah gulungan Motor DC menjadi gulungan WYE (Y) sehingga Motor tersebut menjadi Motor Brushless DC (tanpa sikat). Berikut adalah gambar bentuk dari modifikasi Motor DC.
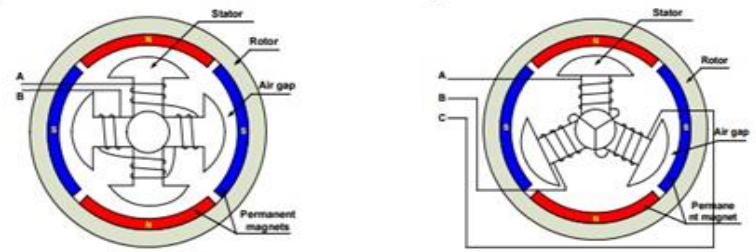

Gbr.1 Modifikasi Motor DCAdapun

Adapun parameter yang diukur yaitu tegangan, arus, daya, frekuensi dan kecepatan Motor Brushless DC.

MOSFET dipasang seri pada kumparan stator motor DC Brushless untuk mengalirkan arus yang terpasang pada polaritas kutub posistif yang dihasilan dioda. Arus gelombang sinus yang dihasilkan akan mengalir ke kumparan stator untuk menggerakan rotor perlahanan sampai mencapai kecepatan putar rotor maksimum, sehingga torsi yang dihasikan rotor konstan dan tidak menimbulkan fluks start yang besar. Kecepatan Motor Brushless DC dikendalikan melalui pengatur frekuensi pada IC NE555 dan CD4017 ke pintu gate MOSFET dengan menyulut tegangan maju secara berkala dari perubahan nilai potensiometer.

Pada mulanya arus dan tegangan searah akan menyuplai keberbagai rangkaian termasuk ke IC dan driver lainnya. Selanjutnya pada tahap awal menjadikannya arus searah menjadi pulsa PWM melalui IC NE555 yang berfungsi sebagai mengatur dan mengubah frekuensi pada pulsa PWM tersebut.

Setelah mengubah frekuensi pulsa PWM melalui IC NE555 selanjutnya diubah sinyal PWM tadi menjadi pulsa decade counter enam logic pulsa menggunakan IC ni CD4017 yang saling bergantian dari satu dan satu lainnya. Untuk enam logic pulsa itidak bisa langsung ke gain MOSFET dikarenakan harus pengkonversian dari enam decade counter ke prinsip logic kerja driver inverter tiga phasa menggunakan beberapa diode. Skema rangkaian control BLDC dan diagram alur penelitian ditunjukkan pada Gambar 2 dan Gambar 3 berturut-turut. 


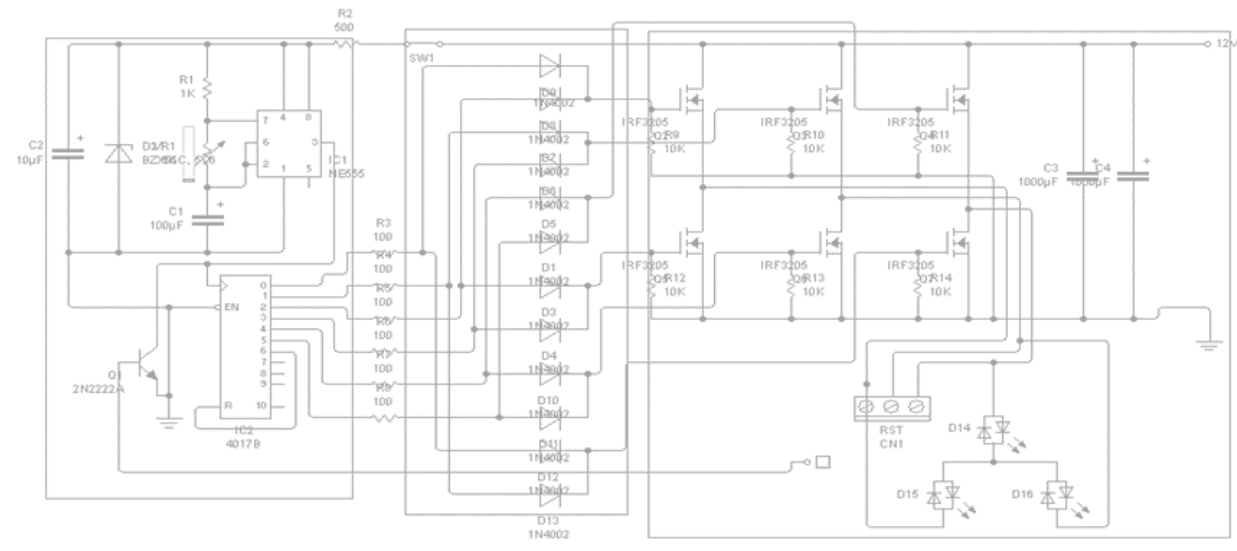

a

b

c

Gbr.2 Skema Rangkaian Kontrol BLDC

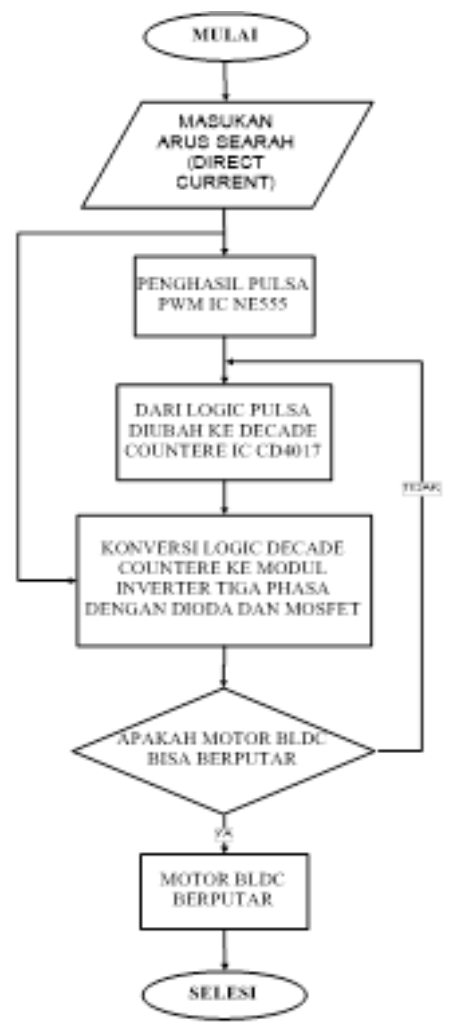

Gbr.3 Diagram alir penelitian

\section{HASIL DAN PEMBAHSAN}

Pengujian Motor Brushless DC dalam dua keadaan, tanpa beban dan berbeban dengan tegangan uji 2,5 Vac, 7,5 Vac, 12,5 Vac, dan 19,5 Vac. Pengujian berbeban menggunakan beban berputar yaitu kipas atau baling-baling ditunjukkan pada Gambar 4.

Nilai frekuensi motor 3 kutub dihitung berdasarkan persamaan 1 berikut :

$$
F=\frac{\operatorname{Rpm} x p}{120}
$$

Hasil kedua pengujian ditunjukkan pada Tabel 1

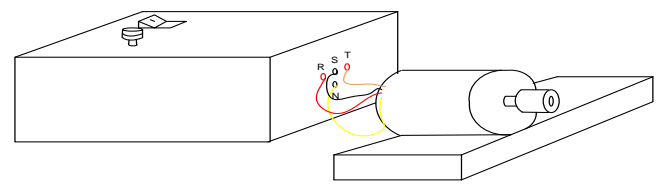

(a)

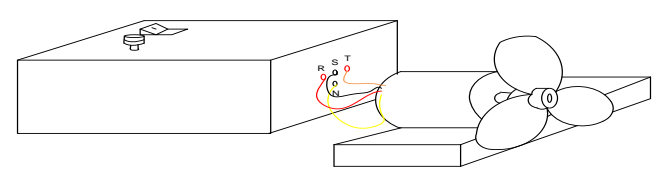

(b)

Gbr.4 Rangkaian Pengujian Motor DC Brushless pada keadaan (a) tak berbeban (b) berbeban 
Tabel 1. Hasil pengujian rangkaian kontrol Motor DC Brushless

\begin{tabular}{|c|c|c|c|c|c|c|c|c|c|}
\hline \multicolumn{10}{|c|}{ Pengujian Tanpa Beban } \\
\hline \multirow{2}{*}{ No } & \multicolumn{2}{|c|}{ Phasa 1} & \multicolumn{2}{|c|}{ Phasa 2} & \multicolumn{2}{|c|}{ Phasa 3} & \multirow{2}{*}{$\underline{\mathrm{Rpm}}$} & \multirow{2}{*}{\multicolumn{2}{|c|}{$\frac{\text { Frekuensi }}{(\mathrm{Hz})}$}} \\
\hline & $\mathrm{V}_{\mathrm{a}}$ & $\mathrm{I}_{\mathrm{a}}$ & $\mathrm{Vb}$ & $\mathrm{Ib}$ & $\mathrm{Vc}$ & Ic & & & \\
\hline 1 & 2,53 & 0,23 & 2,54 & 0,23 & 2,52 & 0,22 & 3800 & \multicolumn{2}{|c|}{95} \\
\hline 2 & 7,54 & 0,45 & 7,55 & 0,44 & 7,57 & 0,46 & 9963 & \multicolumn{2}{|c|}{249} \\
\hline 3 & 12,51 & 0,67 & 12,50 & 0,67 & 12,53 & 0,64 & 15991 & \multicolumn{2}{|c|}{399,77} \\
\hline 4 & 19,53 & 0,86 & 19,55 & 0,85 & 19,54 & 0,87 & 22985 & \multicolumn{2}{|c|}{574,6} \\
\hline \multicolumn{10}{|c|}{ Pengujian Berbeban } \\
\hline \multirow{2}{*}{ No } & \multicolumn{2}{|c|}{ Phasa 1} & \multicolumn{2}{|c|}{ Phasa 2} & & Phasa 3 & Rpm & \multirow{2}{*}{\multicolumn{2}{|c|}{$\frac{\text { Frekuensi }}{(\mathrm{Hz})}$}} \\
\hline & $\mathrm{V}_{\mathrm{a}}$ & $\mathrm{I}_{\mathrm{a}}$ & $\mathrm{Vb}$ & \multicolumn{2}{|c|}{$\mathrm{Ib}$} & $\mathrm{Vc}$ & Ic & & \\
\hline 1 & 2,53 & 0,46 & 2,54 & 0,4 & & 2,52 & 0,47 & 2232 & 55,8 \\
\hline 2 & 7,54 & 0,65 & 7,55 & 0,6 & & 7,57 & 0,65 & 8765 & 219,1 \\
\hline 3 & 12,51 & 0,86 & 12,50 & 0,8 & & 12,53 & 0,87 & 12950 & 323,75 \\
\hline 4 & 19,53 & 1,21 & 19,55 & 1,2 & & 19,54 & 1,22 & 20987 & 524,67 \\
\hline
\end{tabular}

Hasil uji rangkaian menunjukkan bahwa besaran arus pada keadaan berbeban lebih tinggi dibandingkan pada kondisi tak berbeban dengan nilai tegangan yang sama. Berbeda halnya dengan nilai $\mathrm{rpm}$ dan frekuensi, dimana pada kondisi berbeban niali kedua parameter lebih tinggi pada saat motor dibebani. Kedua pengujian menunjukkan nilai rpm berbanding lurus dengan nilai tegangan dan arus. Jika dilihat dari besaran arus per phasa, baik pada kondisi berbeban maupun tidak berbeban besaran arus relative sama. Hasil-hasil ini menunjukkan respon yang baik dari kendali motor Brushless DC menggunakan MOSFET yang dirangkai dengan IC NE555 dan CD4017. Selain itu, melalui pengujian berulang dan pengamatan fisik tidak ditemui adanya peningkatan suhu yang berarti pada rangkaian MOSFET. Sistem feedback pada rangkaian akan mendeteksi error pada motor. Saat terjadi error system feedback akan memberikan umpan balik ke IC CD4017.

Selanjutnya IC CD4017 menerima logic input saat motor berputar dengan fluks yang berpasangan. Pada kondisi ini sistem feedback akan off dan motor kembali berputar pada kecepatan semula.

\section{KESIMPULAN}

Sistem kendali motor DC brushless modifikasi mengunakan IC NE555 dan CD4017 diperkenalkan pada paper ini. Penggunaan kedua komponen ini memberikan hasil pengontrolan kecepatan motor yang baik dan mampu mengatasi masalah MOSFET yang cepat panas, yang umumnya menjadi penyebab mudah rusaknya rangkaian kontrol motor.

\section{REFERENSI}

[1] N. R. Arsya, H. Suryoatmojo, and J. A. R. Hakim, "Desain Kontrol Kecepatan Motor Brushless DC Berbasis Power Factor Correction (PFC) Menggunakan Single Ended Primary Inductance Converter (SEPIC)," vol. 5, no. 2, p. 7, 2016.

[2] H. P. Putra, H. Suryoatmojo, and S. Anam, "Perbaikan Faktor Daya Menggunakan Cuk Converter pada Pengaturan Kecepatan Motor Brushless DC," J. Tek. ITS, vol. 5, no. 2, pp. B156-B162, Sep. 2016, doi: 10.12962/j23373539.v5i2.16097.

[3] D. Akbar and S. Riyadi, "Pengaturan Kecepatan Pada Motor Brushless DC (BLDC) Menggunakan PWM (Pulse Width Modulation)," Bandung, 2018, p. 6.

[4] T. Y. Candra and T. Ta'ali, "Sistem Pengendali Kecepatan Motor DC Penguatan Terpisah Berbeban dengan Teknik Kontrol PWM Berbasis Arduino," Page 1 HttpejournalunpacidindexphpjtevindexJTEV J. Tek. ELEKTRO DAN VOKASIONAL, vol. 6, no. 1, 2020, Accessed: Sep. 26, 2020. [Online].Available:http://webcache.googleus ercontent.com/search?q=cache:qDPPTVeN3 BcJ:ejournal.unp.ac.id/index.php/jtev/article /download/107877/103080+\&cd=13\&hl=id $\& \mathrm{ct}=\mathrm{clnk} \& \mathrm{gl}=\mathrm{id}$.

[5] B. Baharuddin, R. S. Sadjad, and M. Tola, "SISTEM KENDALI KECEPATAN MOTOR DC BERBASIS PWM ( Pulse Width Modulation ) DC MOTOR SPEED CONTROL SYSTEM BASED PWM ( Pulse Wid," Accessed: Sep. 26, 2020. [Online].Available:http://webcache.googleus ercontent.com/search?q=cache:aPctvLupXv gJ:pasca.unhas.ac.id/jurnal/files/0ffe9af51c5 1e48ca3e5da4480a76497.pdf $+\& c d=2 \& h l=i d$ $\& \mathrm{ct}=\mathrm{clnk} \& \mathrm{gl}=\mathrm{id}$.

[6] D. Setiawan, "SISTEM KONTROL MOTOR DC MENGGUNAKAN PWM 


\section{ARDUINO BERBASIS ANDROID} SYSTEM," J. Sains Dan Teknol. Ind., vol. 15, no. 1, Art. no. 1, Dec. 2017, doi: 10.24014/sitekin.v15i1.4131.

[7] O. A. Qudsi, S. Sutedjo, E. Purwanto, and S. D. Nugraha, "Desain dan Implementasi Pengaturan Kecepatan Motor BLDC Melalui Pengaturan Fluks," J. INOVTEK SERI ELEKTRO, vol. 1, no. 1, pp. 36-46, 2019.

[8] T. Suhendra, A. Uperiati, D. A. Purnamasari, and A. H. Yunianto, "Kendali Kecepatan Motor DC dengan Metode Pulse Width Modulation Menggunakan N-channel Mosfet," J. Sustain., vol. 7, no. 2, pp. 78-85, 2018, doi: 10.31629/sustainable.v7i2.701.
[9] S. Duvvada, "A Single Phase to Three Phase PFC Half-Bridge Converter Using BLDC Drive with SPWM Technique," 2014, Accessed: Sep. 26, 2020. [Online]. Available:

[10] J. Linggarjati, “OPTIMASI PENENTUAN JENIS MOSFET PADA PENGENDALI ELEKTRONIKA MOTOR BLDC - PDF Download Gratis," J. Tek. Komput., vol. 2, no. 2, 2012, Accessed: Sep. 26, 2020. [Online]. Available: https://docplayer.info/36704521-Optimasipenentuan-jenis-mosfet-pada-pengendalielektronika-motor-bldc.html. 